\title{
Alternative Therapy of Lisch Epithelial Corneal Dystrophy
}

\author{
Laura Blanca Alfaya Muñoz ${ }^{1 *}$, Javier Celis Sanchez ${ }^{2}$, Diana Mesa Varona ${ }^{2}$ and Eva Maria Avendaño Cantos ${ }^{2}$ \\ ${ }^{1}$ Hospital Universitario de Cabueñes, Spain \\ ${ }^{2}$ Hospital La Mancha Centro, Spain
}

Submission: December 10, 2017; Published: January 03, 2018

*Corresponding author: Laura Blanca Alfaya Muñoz, Hospital Universitario de Cabueñes, Spain, Tel: (+34) 661683370;

Email: laura.alfaya@gmail.com

\section{Introduction}

Corneal dystrophies produced a gradual bilateral loss of vision without red eye associated. In 1992 Lisch [1] described a corneal epithelial dystrophy, characterized as band-shaped and whorled microcystic dystrophy of the corneal epithelium. This opacity affected the vision only when visual axis was involved by clear densely crowed microcysts. No epithelial erosions were associated. The Lisch epithelial corneal dystrophy (LECD) locus [2] was identified within or near X chromosome dominant by molecular genetics, but there were further reports of sporadic bilateral or unilateral cases [3]. Scraping the epithelium [4] or soft contact lens [5] were been the conventional treatment when blurred vision was appeared.

We report a case of 8 years follow-up female patient with LECD that failured after conventional techniques treatment and presented complete resolution after microsurgery limbar autograft transplantation.

\section{Case Presentation}

A 58-year-old female patient with no familiar history of corneal epithelial dystrophy reported of gradual blurry vision and painless loss of visual acuity in the right eye. Her best corrected visual acuity (BCVA) was 20/40 in the right eye and $20 / 20$ in the left eye. Slit-lamp examination showed a gray, band-shaped opacity in the central corneal epithelium in the right eye. This fearthery corneal opacification was extended from the superior periphery up to the visual axis. Involved areas showed a sharp demarcation with clear surrounding epithelium. The dense microcysts pattern were better saw with retroillumination. Fluorescein dye staining was negative and no conjuntival injection was present. The cornea of the left eye revealed no alterations. No other alterations were found in anterior or posterior pole (Figure 1).

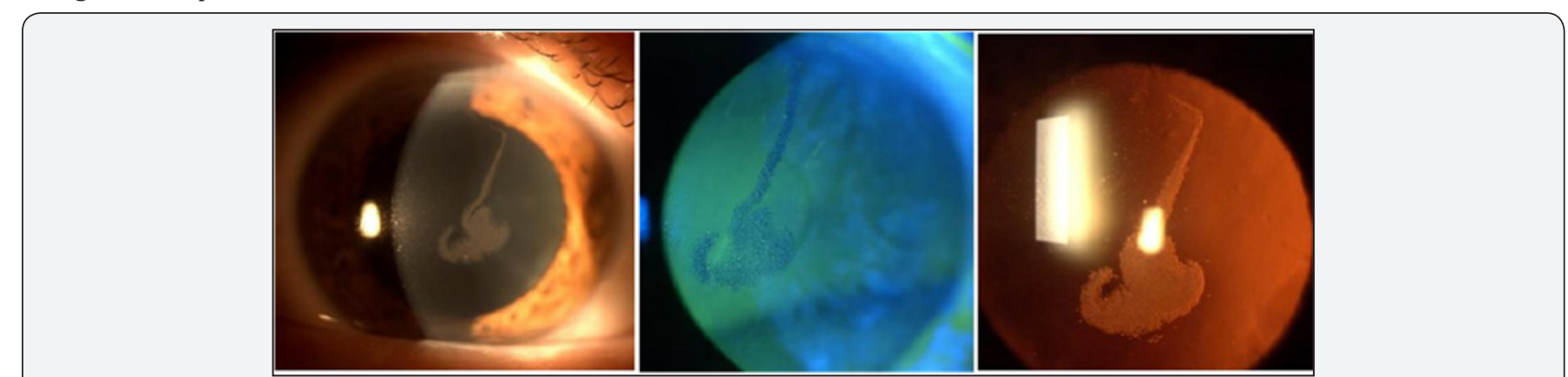

Figure 1: Slit-lamp photograph of the right cornea. A. Diffuse opacity in the epithelium cornea. B. Fluorescein dye staining. C. Dense microcysts pattern with retroillumination.

Scraping of the corneal epithelium was performed. The topical therapy were tobramycin every 6 hours and soft contact lens 7 days ago. Histopathology examination revealed scattered areas of vacuoles optically empty without atypical cells. The cytoplasm was dense and clear. Cell borders and enlarged nuclei were visible. Immunohistochemistry revealed p53 negative cells.

Reepithelization occurred in few days with normal clear epithelium but new scraping was necessary at 7 months ago.
Microcysts appeared again three more times over two years causing loss of vision because of its visual axis involvement. Topical Mitomycin C were used without success (Figure 2).

At 39 months her BCVA in the right eye was 20/50. Slitlamp examination showed a gray, band-shaped opacity in the central corneal epithelium involvement higher than in other explorations. 

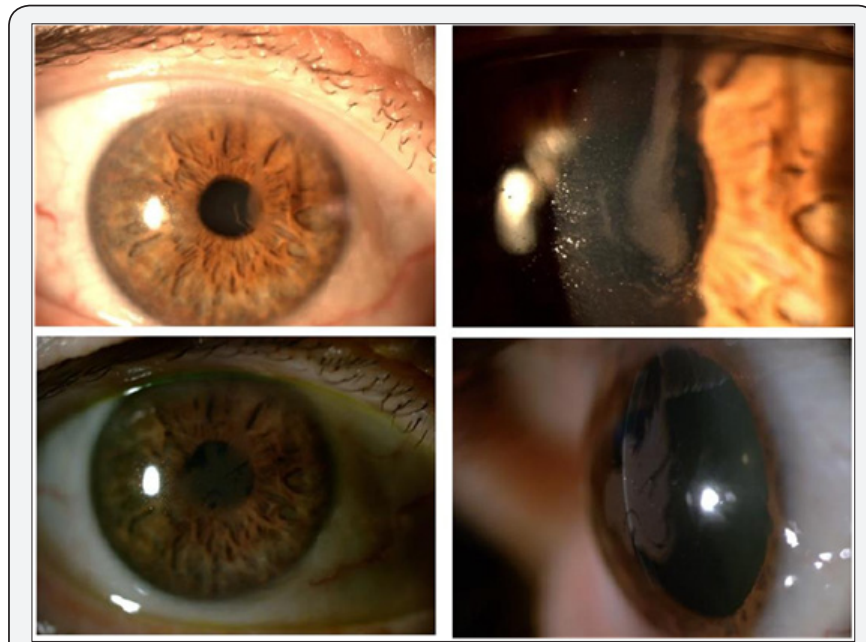

Figure 2: A and B. Gray, band-shaped, and feathery corneal opacification extending from the superior periphery up to the visual axis after scraping 7 months ago. C and D. Microcysts appeared again and the central corneal epithelium involvement higher than in other explorations after mitomycin-C.

Microsurgery limbar autograft transplantation was performed without complications. We removed a strip of conjunctival-free limbal grafts from the superior limbus of the left donor eye through superficial lamellar keratectomy and blunt dissection. The right eye was prepared by superficial keratectomy to remove the epithelium. A conjunctival incision was made to expose the limbus and perilimbal sclera at the graft superior location. The graft was put in place and sutured to the limbus and sclera using interrupted 10-0 nylon sutures and 8-0 vicryl sutures, respectively.

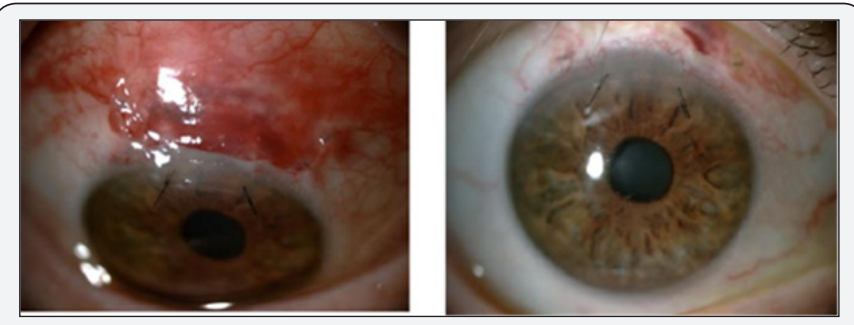

Figure 3 : Postoperatory eye.

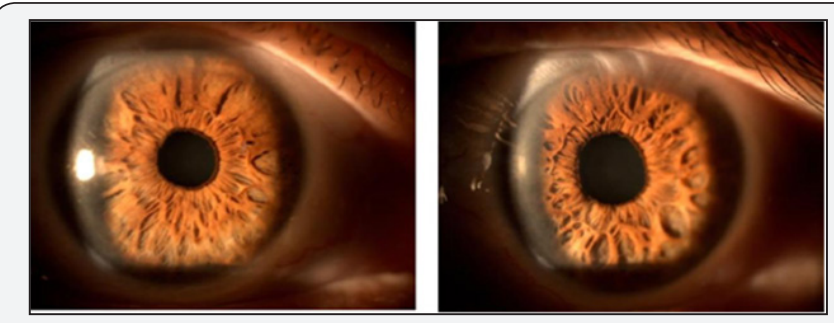

Figure 4 : Both eyes after 4 years of limbar autograft transplantation.

Postoperative care included protective soft contact lens, autologous serum eye drops, and a short-term course of tobramycin and topical prednisolone acetate (Figure 3). After four years of surgery remains healthy epithelium with clear cornea. There is no evidence of recurrence of the dystrophy after limbar autograft transplantation in the right eye. There is a small conjunctival invasion in the donor site on the left eye. Her BCVA are 20/20 in both eyes (Figure 4).

\section{Discussion}

LECD is a epithelial dystrophy that causes slow gradual blurred vision if the pupillary zone is involved [6]. In other cases, it could be asymptomatic and lesions are found incidentally. Light microscopy shows diffuse cytoplasmic vacuolization of all cells in the affected area, most evident at the wing cell layer, with a sharp delineation from non affected áreas.

Limbal transplantation is a surgical technique of ocular surface epithelial trasplantation advocated for a variety of ocular surface disorders with presumed stem-cell deficiency [7]. The LECD locus [2] was identified in Xp 22.3 chromosome dominant by molecular genetics, but the gen remained to be identified. In this case, our patient presented a unilateral case, so we concluded that it could be a sporadic case. This allowed the successful treatment with limbal transplantation.

\section{Conclusion}

The Lisch epithelial dystrophy is described by itself as a new entity [1]. This can be confirmed by clinical and histopathological findings [6]. A different locus to other epithelial dystrophies entity was been discovered [2]. The treatment for this disease were corneal scraping or contact lenses, with different results [3-5].

We presented a microsurgical alternative limbar autograft transplantation for unilateral LECD when other techniques failed.

\section{References}

1. Lisch W, Steuhl KP, Lisch C, Weidle EG, Emmig CT, et al. (1992) A new band-shaped and whorled microcystic dystrophy of the corneal epithelium. Am J Ophthalmol 114(1): 35-44.

2. Lisch W, Büttner A, Oeffner F, Böddeker I, Engel H, et al. (2000) Lisch corneal dystrophy is genetically distinct from Meesmann corneal dystrophy and maps to Xp22.3 Am J Ophthalmol 130(4): 461-468.

3. Alvarez-Fischer M, de Toledo JA, Barraquer RI (2005) Lisch corneal dystrophy. Cornea 24(4): 494-495.

4. Seitz B, Lisch W (2011) Stage-related therapy of corneal dystrophies. Dev Ophthalmol 48: 116-153.

5. Lisch W, Wasielica-Poslednik J, Lisch C, Saikia P, Pitz S (2010) Contact Lens-Induced Regression of Lisch Epithelial Corneal Dystrophy. Cornea 29(3): 342-345.

6. Weiss JS, Møller HU, Lisch W, Kinoshita S, Aldave AJ, et al. (2008) The IC3D classification of the corneal dystrophies. Cornea 27 Suppl 2: S1S83.

7. Health Quality Ontario (2008) Limbal stem cell transplantation: an evidence-based anaysis. Ont Health Technol Assess Ser 8(7): 1-58. 
This work is licensed under Creative Commons Attribution 4.0 License

DOI: $10.19080 /$ JOJO.2018.06.555680
Your next submission with Juniper Publishers will reach you the below assets

- Quality Editorial service

- Swift Peer Review

- Reprints availability

- E-prints Service

- Manuscript Podcast for convenient understanding

- Global attainment for your research

- Manuscript accessibility in different formats

( Pdf, E-pub, Full Text, Audio)

- Unceasing customer service

Track the below URL for one-step submission https://juniperpublishers.com/online-submission.php 